Original article

\title{
Variability, Correlation, and Path Coefficient Analysis of Grain Yield and Yield-Related Traits of Facultative Barley Accessions Grown Under Rainfed Conditions
}

\author{
Nikolay Dyulgerov (iD) a, " \& Boryana Dyulgerova ${ }^{\text {a }}{ }^{\text {a }}$ \\ ${ }^{a}$ Instutute of Agriculture - Karnobat, Agricultural Academy, Bulgaria
}

\begin{abstract}
The aim of the present study was to investigate the variability, heritability, and correlation between grain yield and yield-related traits of breeding lines of facultative barley under rainfed conditions and to select lines with desirable agronomic traits for including in further breeding work for the development of facultative barley varieties for Bulgarian environments. The study was conducted during the period of three concessive years from 2016/2017 to 2018/2019 in the experimental field of the Institute of Agriculture - Karnobat, Southeastern Bulgaria. The traits: number of days to heading, plant height, spike length, spikelet number per spike, grain number per spike, grain weight per spike, and grain yield were recorded. The analysis of variance indicated significant differences between 6-rowed facultative barley genotypes in the studied traits. Most of the traits under the study showed a relatively low phenotypic and genotypic coefficient of variation. The estimates for heritability in broad-sense were high for the number of days to heading, grain weight per spike, and 1000-grain weight and very high for plant height and spike length suggesting a possibility for improvement of those traits through selection based on phenotype. Whereas low heritability of grain yield was found indicating that the phenotypic selection could be ineffective under these specific conditions. Grain yield of facultative barley accessions showed a significant positive correlation with spike length, spikelet number per spike, grain number per spike, and grain weight per spike. The traits with the highest positive direct effect on grain yield were grain number per spike and 1000-grain weight while days to heading had a highly negative direct effect on grain yield. A combination of high heritability and high direct on grain yield in 1000-grain weight and days to heading shows that those traits may be used in early-generation selection in breeding of high-yielding facultative lines. The accession TX01D236 had a significantly higher grain yield compared to check varieties and could be included in future breeding work.
\end{abstract}

Keywords: Facultative barley, Variability, Heritability, Correlation, Grain yield, Yield-related traits.

Received: 08 April $2021 *$ * Accepted: 25 June $2021 \quad * \quad$ DOI: https://doi.org/10.29329/ijiaar.2021.358.5

\footnotetext{
* Corresponding author:

Dyulgerov Nikolay is an assistant professor at the Institute of Agriculture in Karnobat, Bulgaria. His research interests include barley breeding, evaluation, and preservation of barley genetic resources. He has a PhD in Plant breeding and seed production, Institute of Agriculture - Karnobat. Email: ndyulgerov@abv.bg
} 


\section{INTRODUCTION}

Barley (Hordeum vulgare L.) is one of the most important cereal crops in the world, mostly used for animal feed and malt. In Bulgaria, barley is cultivated mainly as a winter crop under rainfed conditions. The climate in Southeast Bulgaria is sufficiently humid (annual sum of precipitation about $550 \mathrm{~mm}$ ) with mild winter and dry and hot summer. In those conditions, winter barley has a higher yield performance compared to spring barley. However, there is interest in growing spring barley especially when conditions do not allow timely sowing in the fall or there is a need for recultivation of areas with winter-killed fall-sown crops. Also, spring barley is cultivated in higher altitudes and in other regions where there is a high risk of low temperature-induced crop injury. Crop production under rainfed conditions faces many challenges that are increasing because of climate change, which already resulted in increased average air temperatures and high inter-annual and intra-annual variability of precipitation as well as to climate extremes, such as drought and floods.

In the context of climate change and climate volatility, the facultative growth habit is an advantage as it could give growers maximum flexibility because the same cultivar could be planted in the fall or in the spring. Facultative barley is characterized by high low-temperature tolerance, sensitivity to shortday photoperiod, and no vernalization requirement (von Zitzewitz et al., 2011). However, despite the value of facultative barley, in the Bulgarian cultivar list are included only two old barley cultivars (Veslets and Emon) which suggest that breeding work for the development of new higher-yielding varieties of this type is needed.

In any breeding program, the availability of the genetic variability for the agronomic traits of commercial interest is of fundamental importance (Muñoz-Amatriaín et al., 2014). The assessment of accessions from the new germplasm is provided knowledge for their productive potential and adaptability to the local conditions. The quantifying the magnitude of the variability and extension in which the desirable characters are inherited allowed planning of an effective program of genetic improvement (Tazeen et al., 2009). Knowledge of the interrelationship of the characters is extremely valuable for the breeding strategies, especially when the selection of a trait assists improvement in other correlated characters (Neyhart et al., 2019). The information for the heritability of important characters is essential for most quantitative traits that are strongly influenced by the environment. This shows that studies of the genetic resources of barley are fundamental, especially when considering elite genotypes with good agronomic traits, originating from different plant breeding programs.

The aim of the present study was to investigate the variability, heritability, and correlation between grain yield and yield-related traits of 23 breeding lines of facultative barley from the Texas A\&M University breeding program and to select accessions with desirable agronomic traits for including in further breeding work for the development of facultative barley varieties for Bulgarian environments. 


\section{MATERIALS and METHODS}

\section{Experimental site location}

The study was conducted during the period of three concessive years from 2016/2017 to 2018/2019 in the experimental field of the Institute of Agriculture - Karnobat, Southeastern Bulgaria $\left(42^{\circ} 39^{\prime} 0^{\prime \prime} \mathrm{N} / 26^{\circ} 58^{\prime} 60^{\prime \prime} \mathrm{E}\right)$. The soil of the experimental field was slightly acid (pH is 6.2) Pellic Vertisol.

Average temperatures and sums of precipitation during the experimental period are shown in Table 1. The sum of precipitation for the vegetation period compared to the long-term average precipitation for the location was lower in the first year (with $111.3 \mathrm{~mm}$ ), and third year (with $73.0 \mathrm{~mm}$ ), and extremely higher in the second year (with $485.9 \mathrm{~mm}$ ). The average temperatures of growing seasons were higher than the long-term average monthly temperatures.

Tables 1. Average air temperature, monthly sums of precipitation and long-term average data in Karnobat, Southeastern Bulgaria during barley vegetation (2016/2017- 2018/2019)

\begin{tabular}{|c|c|c|c|c|c|c|c|c|}
\hline \multirow{2}{*}{ Months } & \multicolumn{2}{|c|}{$2016 / 2017$} & \multicolumn{2}{|c|}{$2017 / 2018$} & \multicolumn{2}{|c|}{$2018 / 2019$} & \multicolumn{2}{|l|}{$\mathrm{LT}$} \\
\hline & $\mathrm{T},{ }^{\circ} \mathrm{C}$ & $\mathrm{P}, \mathrm{mm}$ & $\mathrm{T},{ }^{\circ} \mathrm{C}$ & $\mathrm{P}, \mathrm{mm}$ & $\mathrm{T},{ }^{\circ} \mathrm{C}$ & $\mathrm{P}, \mathrm{mm}$ & $\mathrm{T},{ }^{\circ} \mathrm{C}$ & $\mathrm{P}, \mathrm{mm}$ \\
\hline $\mathrm{X}$ & 12.1 & 67.0 & 12.5 & 270 & 14.0 & 15.4 & 12.5 & 44.3 \\
\hline XI & 7.5 & 36.9 & 8.4 & 38.8 & 7.4 & 68.3 & 7.1 & 53.7 \\
\hline XII & 0.6 & 5.7 & 5.2 & 93.1 & 2.4 & 27.3 & 2.6 & 51.2 \\
\hline I & -2.5 & 28.9 & 2.5 & 49.0 & 2.5 & 38.9 & 0.6 & 36.5 \\
\hline II & 3.7 & 32.9 & 3.5 & 81.1 & 4.3 & 15.6 & 2.2 & 35.8 \\
\hline III & 8.3 & 24.1 & 6.4 & 121.2 & 8.6 & 8.9 & 5.3 & 34.1 \\
\hline IV & 10.0 & 35.4 & 19.3 & 6.0 & 10.3 & 52.9 & 10.5 & 45.3 \\
\hline V & 16.1 & 36.6 & 17.9 & 68.6 & 17.1 & 44.9 & 15.6 & 58.5 \\
\hline VI & 21.7 & 55.0 & 20.8 & 98.6 & 22.6 & 95.6 & 19.6 & 65.2 \\
\hline VII & 23.4 & 40.7 & 23.1 & 134 & 22.9 & 33.7 & 22.0 & 49.9 \\
\hline $\mathrm{T},{ }^{\circ} \mathrm{C}$ & 10.1 & - & 12.0 & - & 11.2 & - & 9.8 & - \\
\hline $\mathrm{P}, \mathrm{mm}$ & - & 363.2 & - & 960.4 & - & 401.5 & - & 474.5 \\
\hline
\end{tabular}

$\mathrm{T}$ - average air temperature; $\mathrm{P}$ - sum of precipitation; LT - long-term average air temperature and sum of precipitation (1931-2019)

\section{Experimental Materials}

The trial consisted of 23 six-rowed facultative barley lines and as checks were included six-rowed facultative varieties - Bulgarian variety Veslets and German variety Borwina. The breeding lines were obtained from the USDA National Small Grain Collection and were developed at Texas A\&M University. The pedigree of the accessions used in the study is presented in Table 2. 
Tables 2. Pedigree of the breeding lines of facultative barley used in the study

\begin{tabular}{lll}
\hline № & Breeding line & Pedigree \\
\hline 1 & TX01D109 & OK95939/OK92911 \\
2 & TX01D110 & OK95939/OK92911 \\
3 & TX01D127 & 91AB7655/VA92-42-52 \\
4 & TX01D132 & Robust/TAMBAR 500//OK90813 \\
5 & TX01D133 & Robust/TAMBAR 500//OK90813 \\
6 & TX01D135 & ND11116/OK84817 \\
7 & TX01D136 & ND11116/OK84817 \\
8 & TX01D142 & M44/VA84-44-342//OK87807 \\
9 & TX01D144 & M44/VA84-44-342//OK87807 \\
10 & TX01D221 & 87AB9478/WA1997-87//M75/NE86594 \\
11 & TX01D234 & B1614/92AB561 \\
12 & TX01D236 & B1614/92AB561 \\
13 & TX01D237 & B1614/NE92711 \\
14 & TX01D242 & B1614/NE92711 \\
15 & TX01D243 & B1614/SC890202 \\
16 & TX01D252 & W10489-86/92AB561 \\
17 & TX01D305 & OK96858/OK94848 \\
18 & TX01D306 & OK96858/OK94848 \\
19 & TX01D310 & M44/NE90710//ORW11 \\
20 & TX01D335 & M44/NE90710//OK96887 \\
21 & TX01D390 & Robust/Excel//WA10489-86/3/86AB474-P- \\
22 & TX01D391 & Robust/Excel//WA10489-86/3/86AB474-P- \\
23 & TX02D290 & VA72-42-45/SC793556/C12457 \\
\hline
\end{tabular}

\section{Experimental Design}

The experiments were organized in a Randomized Complete Block Design with 3 replications on plots of $3.6 \mathrm{~m}^{2}$. During the growing seasons, standard plant protection practices were used.

\section{Data Collection}

The traits: plant height $(\mathrm{cm})$, spike length $(\mathrm{cm})$, spikelet number per spike, grain number per spike, grain weight per spike (g) were recorded on 25 randomly selected plants in each replication for each genotype. The number of days to heading was recorded as the number of days from the sowing date to the date of the appearance of $50 \%$ of spikes. Grain yield (t/ha) and 1000-grain weight (g) were estimated on plot basis.

\section{Statistical analysis}

Analysis of variance and Pearson's linear correlation coefficients among traits was computed by using SPSS 17.00 for Windows (SPSS, 2008). The phenotypic coefficient of variation (PCV) and 
genotypic coefficient of variation (GCV) were determined as low - less than $10 \%$, medium - between 10 and 20\% and high - greater than 20\% (Deshmukh et al., 1986). Broad-sense heritability $\left(\mathrm{h}^{2}\right)$ was calculated as the ratio of the genotypic variance to the phenotypic variance. Heritability estimates were grouped into the following categories: low $<40 \%$, medium - 40-59\%, high - 60-79\% and very high heritability $>80 \%$ (Singh, 2001). The path analysis performed by using the statistical software GENES (Cruz, 2001) was used to split correlations between grain yield (dependent variable) and other traits into direct and indirect effects.

\section{RESULTS and DISCUSSION}

Analysis of variance showed a highly significant effect ( $\mathrm{p}<0.01)$ of genotype, year and genotype $\mathrm{x}$ year interaction on the variation of all studied traits (Table 3). The phenotypic coefficient of variation (PCV) ranged from $0.89 \%$ for number of days to heading to $19.17 \%$ for grain yield. PCV values were moderate for grain yield (20.97\%) and spike length (14.86\%). Low PCV values were observed for plant height $(7.87 \%)$, number of days to heading $(0.89 \%)$, spikelet $(5.70 \%)$ and grain $(6.96 \%)$ number per spike $(6.96 \%)$, grain weight per spike (9.88\%) and 1000-grain weight (6.60\%). All the traits under study except spike length showed the relatively low genotypic coefficient of variation (GCV). The difference between the phenotypic coefficient of variation and the genotypic coefficient of variation was highest for grain yield. This difference was low for plant height and number of days to heading indicating a high possibility for effective selection based on the phenotype.

Low heritability values were observed only for grain yield (14.94\%) which suggests that direct selection for yield would be considerably difficult due to the masking effect of the environment (Table 3). Heritability was medium for spikelet number per spike $(44.88 \%)$ and grain number per spike (45.99\%). High values of heritability were found for number of days to heading (63.70\%), grain weight per spike $(62.89 \%)$ and 1000-grain weight $(78.58 \%)$. Very high heritability was observed for plant height $(90.52 \%)$ and spike length $(91.06 \%)$. Low values of broad-sense heritability for barley grain yield were also found by Ahmadi et al. (2016) while other authors reported from medium (Sayd et al. 2019) to high (Al-Tabbal et al., 2012) heritability estimates. 
Table 3. Mean squares (MS), phenotypic coefficient of variation (PCV), genotypic coefficient of variation $(\mathrm{GCV})$, and broad-sense heritability $\left(\mathrm{h}^{2}\right)$ of studied traits of facultative barley accessions

\begin{tabular}{lllllll}
\hline Traits & $\mathbf{M S}$ & $\mathbf{M S}$ & $\mathbf{M S}$ & $\mathbf{P C V}, \boldsymbol{\%}$ & $\mathbf{G C V}, \boldsymbol{\%}$ & $\mathbf{h}^{2}, \boldsymbol{\%}$ \\
& $\mathbf{G}$ & $\mathbf{E}$ & $\mathbf{G x E}$ & & & \\
\hline GY & $8.59^{*}$ & $165.17^{*}$ & $7.30^{*}$ & 19.17 & 7.41 & 14.94 \\
PH & $598.10^{*}$ & $8215.27^{*}$ & $56.67^{*}$ & 7.87 & 7.49 & 90.52 \\
DH & $34.85^{*}$ & $679.59^{*}$ & $12.65^{*}$ & 0.89 & 0.71 & 63.70 \\
SL & $10.82^{*}$ & $18.76^{*}$ & $0.97^{*}$ & 14.86 & 14.18 & 91.06 \\
SNS & $150.25^{*}$ & $259.54^{*}$ & $82.82^{*}$ & 5.70 & 3.82 & 44.88 \\
GNS & $159.79^{*}$ & $2277.10^{*}$ & $86.30^{*}$ & 6.96 & 4.72 & 45.99 \\
GWS & $0.58^{*}$ & $8.72^{*}$ & $0.22^{*}$ & 9.88 & 7.83 & 62.89 \\
HGW & $94.65^{*}$ & $448.46^{*}$ & $20.27^{*}$ & 6.60 & 5.85 & 78.58 \\
\hline
\end{tabular}

G - genotype; E - environment; GxE - genotype by environment interaction; "significant at 0.01 level; GY - grain yield; PH- plant height; DH - number of days to heading; SL - spike length; SNS - spikelet number per spike; GNS - grain number per spike; GWS - grain weight per spike; TGW - 1000-grain weight;

The mean values of studied traits of facultative barley accessions are presented in Table 4. Grain yield of the check varieties Veslets and Borwina was $5.81 \mathrm{t} / \mathrm{ha}$ and $5.38 \mathrm{t} / \mathrm{ha}$, respectively. The average grain yield of the accessions varied from 3.23 t/ha (TX02D290) to $6.77 \mathrm{t} / \mathrm{ha}$ (TX01D236). Only one accession TX01D236 had a significantly higher grain yield compared to variety Veslets. All other accessions except TX01D242 showed significantly lower grain yield compared to the higher-yielding check Veslets. Plant height of accessions ranged from $74.44 \mathrm{~cm}$ (TX01D243) to $111.22 \mathrm{~cm}$ (TX01D221). A higher number of days to heading than in Veslets was found in variety Borwina and in TX01D236, TX01D305, TX01D310, TX01D135, and TX01D390. The longest spike $(8.01 \mathrm{~cm})$ was measured in variety Borwina while TX01D132 had the shortest spike $(4.16 \mathrm{~cm})$. Accessions TX01D236 and TX01D335 had a higher number of spikelets and grains per spike compared to Veslets. The maximum value for grain weight per spike was recorded in TX01D236 $(2.77 \mathrm{~g})$ and the minimum value in TX01D243 (1.59 g). The mean 1000-grain weight of check varieties was $46.73 \mathrm{~g}$ for Veslets and $46.38 \mathrm{~g}$ for Borwina. Most of the studied accessions showed significantly lower 1000-grain weight than checks.

The correlation coefficients between grain yield and yield-related traits are presented in Table 5. Grain yield of facultative barley accessions showed a significant positive correlation with spike length $(\mathrm{r}=0.531)$, spikelet number per spike $(\mathrm{r}=0.653)$, grain number per spike $(\mathrm{r}=0.676)$ and grain weight per spike $(\mathrm{r}=0.704)$. A positive and significant correlation of number of days to heading with spike length $(\mathrm{r}=0.480)$ and 1000-grain weight $(\mathrm{r}=0.422)$ was observed. Spike length was accosted with grain weight per spike $(r=0.765)$ and 1000-grain weight $(r=0.670)$. Spikelet number per spike correlated with grain number per spike $(r=0.795)$ and grain weight per spike $(r=0.531)$. A significant association of grain weight per spike with grain number per spike $(r=0.644)$ and 1000 -grain weight $(r=0.668)$ was also found. 
Tables 4. The mean values of studied traits of 23 facultative barley accessions and check varieties

\begin{tabular}{|c|c|c|c|c|c|c|c|c|}
\hline Accessions & GY & PH & DH & SL & NSS & NGS & GWS & HGW \\
\hline Veslets & 5.81 & 88.78 & 190.00 & 7.12 & 64.20 & 52.81 & 2.35 & 46.73 \\
\hline Borwina & 5.38 & 90.33 & 192.89 & 8.01 & 65.25 & 54.49 & 2.54 & 46.38 \\
\hline TX01D109 & 4.16 & 86.78 & 187.89 & 6.76 & 61.80 & 52.10 & 2.16 & 39.60 \\
\hline TX01D110 & 4.67 & 88.67 & 190.00 & 5.96 & 56.69 & 48.81 & 2.08 & 40.34 \\
\hline TX01D127 & 4.17 & 82.78 & 190.00 & 4.89 & 66.47 & 54.38 & 2.39 & 39.19 \\
\hline TX01D132 & 3.47 & 75.11 & 187.44 & 4.16 & 59.44 & 43.99 & 1.75 & 40.14 \\
\hline TX01D133 & 4.26 & 82.78 & 189.33 & 6.26 & 57.87 & 49.37 & 2.02 & 41.45 \\
\hline TX01D135 & 3.56 & 80.44 & 193.67 & 7.07 & 63.07 & 54.66 & 2.27 & 40.27 \\
\hline TX01D136 & 4.39 & 96.00 & 188.44 & 6.41 & 59.83 & 51.56 & 2.30 & 41.87 \\
\hline TX01D142 & 5.21 & 96.11 & 190.67 & 6.81 & 64.97 & 55.02 & 2.43 & 43.86 \\
\hline TX01D144 & 3.23 & 100.33 & 191.22 & 6.89 & 60.90 & 50.81 & 2.12 & 43.23 \\
\hline TX01D221 & 3.74 & 111.22 & 192.22 & 6.40 & 58.16 & 51.63 & 2.19 & 42.49 \\
\hline TX01D234 & 5.21 & 90.44 & 190.78 & 7.65 & 65.92 & 55.17 & 2.44 & 45.07 \\
\hline TX01D236 & 6.77 & 93.22 & 194.11 & 7.81 & 70.80 & 63.04 & 2.77 & 47.58 \\
\hline TX01D237 & 4.57 & 95.22 & 189.44 & 4.87 & 60.42 & 54.57 & 2.12 & 40.09 \\
\hline TX01D242 & 5.69 & 85.78 & 191.67 & 7.56 & 65.45 & 54.73 & 2.58 & 44.50 \\
\hline TX01D243 & 2.99 & 74.44 & 192.78 & 4.51 & 61.75 & 48.39 & 1.59 & 36.02 \\
\hline TX01D252 & 5.13 & 84.11 & 192.78 & 7.31 & 64.00 & 50.47 & 2.19 & 41.58 \\
\hline TX01D305 & 3.35 & 85.00 & 193.11 & 6.16 & 54.00 & 45.87 & 2.08 & 46.70 \\
\hline TX01D306 & 3.85 & 94.56 & 190.11 & 6.19 & 54.62 & 48.38 & 2.38 & 47.17 \\
\hline TX01D310 & 3.26 & 96.44 & 193.89 & 6.90 & 63.90 & 51.67 & 2.23 & 43.74 \\
\hline TX01D335 & 5.48 & 93.44 & 188.11 & 5.39 & 68.05 & 61.05 & 2.13 & 35.83 \\
\hline TX01D390 & 4.07 & 96.11 & 193.11 & 6.83 & 61.79 & 52.81 & 2.37 & 45.11 \\
\hline TX01D391 & 4.56 & 82.00 & 191.78 & 7.29 & 64.29 & 54.12 & 2.34 & 43.55 \\
\hline TX02D290 & 3.30 & 91.78 & 190.67 & 4.58 & 59.17 & 49.97 & 1.92 & 40.89 \\
\hline LSD 0.05 & 0.14 & 3.83 & 2.82 & 0.49 & 3.00 & 3.02 & 0.38 & 1.72 \\
\hline
\end{tabular}

GY - grain yield; PH- plant height; DH - number of days to heading; SL - spike length; SNS - spikelet number per spike; GNS - grain number per spike; GWS - grain weight per spike; TGW - 1000-grain weight;

Table 5. Phenotypic correlations among the traits

\begin{tabular}{cccccccc}
\hline Traits & PH & DH & SL & SNS & GNS & GWS & HGW \\
\hline GY & 0.091 & -0.014 & $0.531^{* *}$ & $0.653^{* *}$ & $0.676^{* *}$ & $0.704^{* *}$ & 0.333 \\
PH & & 0.083 & 0.252 & -0.051 & 0.294 & 0.354 & 0.317 \\
DH & & & $0.480^{*}$ & 0.198 & 0.16 & 0.305 & $0.422^{*}$ \\
SL & & & & 0.385 & 0.377 & $0.765^{* *}$ & $0.670^{* *}$ \\
SNS & & & & & $0.795^{* *}$ & $0.531^{* *}$ & -0.008 \\
GNS & & & & & & $0.644^{* *}$ & 0.030 \\
GWS & & & & & & & $0.668^{* *}$ \\
\hline
\end{tabular}

${ }^{*},{ }^{* *}:$ significant at 0.05 and 0.01 level, respectively; GY - grain yield; PH- plant height; DH - number of days to heading; SL - spike length; SNS - spikelet number per spike; GNS - grain number per spike; GWS - grain weight per spike; TGW - 1000-grain weight; 
Similar correlations between grain yield and yield components that were observed in present study were also reported by Madić et al. (2019), Negash et al. (2019) and Aklilu et al. (2020).

The direct and indirect effects of studied traits on grain yield are presented in Tables 6 . The path coefficient analysis revealed that the grain number per spike (0.528) had the highest positive direct effect on grain yield followed by 1000 -grain weight $(0.402)$. The number of days to heading $(-0.400)$ had a highly negative direct effect on grain yield. A moderate positive direct effect of spike length (0.215) and spikelet number per spike (0.216) on grain yield was found. While the direct effect of plant height (0.205) was moderate and negative. The maximum positive indirect effect was recorded by spikelet number per spike (0.420) via grain number per spike and by grain weight per spike (0.340) also via grain number per spike.

Table 6. Path analysis showing direct and indirect effect of traits on grain yield

\begin{tabular}{cccccccccc}
\hline \multirow{2}{*}{ Traits } & Direct effect & \multicolumn{9}{c}{ Indirect effect } & \multirow{2}{*}{ Total effect } \\
\cline { 3 - 9 } & & PH & DH & SL & SNS & GNS & GWS & HGW & \\
\hline PH & -0.205 & & -0.033 & 0.054 & -0.011 & 0.155 & 0.004 & 0.127 & 0.091 \\
DH & -0.400 & -0.017 & & 0.103 & 0.043 & 0.085 & 0.003 & 0.169 & -0.014 \\
SL & 0.215 & -0.052 & -0.192 & & 0.083 & 0.199 & 0.009 & 0.269 & 0.531 \\
SNS & 0.216 & 0.010 & -0.079 & 0.083 & & 0.420 & 0.006 & -0.003 & 0.653 \\
GNS & 0.528 & -0.060 & -0.064 & 0.081 & 0.172 & & 0.007 & 0.012 & 0.676 \\
GWS & 0.011 & -0.073 & -0.122 & 0.164 & 0.115 & 0.340 & & 0.268 & 0.704 \\
HGW & 0.402 & -0.065 & -0.169 & 0.144 & -0.002 & 0.016 & 0.007 & & 0.333 \\
\hline
\end{tabular}

PH- plant height; DH - number of days to heading; SL - spike length; SNS - spikelet number per spike; GNS - grain number per spike; GWS - grain weight per spike; TGW - 1000-grain weight; GY - grain

The results from the path analysis are in agreement with those reported from Zaefizadeh et al. 2011, who also showed highest direct positive effect on yield by number of grains per main spike and highest negative direct effect by days to heading.

The high impact of the heading date on grain yield observed in our study confirmed the importance of this trait for barley adaptability to different stresses such as heat stress, waterlogging, and drought. Our findings support the significance of the number of grains per spike and grain weight for barley grain yield under rainfed conditions.

\section{CONCLUSION}

The analysis of variance indicated significant differences between 6-rowed facultative barley genotypes in the studied traits. Most of the traits under the study showed the relatively low phenotypic and genotypic coefficient of variation. The estimates for heritability in broad-sense were high for the number of days to heading, grain weight per spike, and 1000-grain weight and very high for plant height and spike length suggesting a possibility for improvement of those traits through selection based on 
phenotype. Whereas low heritability of grain yield was found indicating that the phenotypic selection could be ineffective under these specific conditions. Grain yield of facultative barley accessions showed a significant positive correlation with spike length, spikelet number per spike, grain number per spike and grain weight per spike. The traits with the highest positive direct effect on grain yield were grain number per spike and 1000-grain weight while days to heading had a highly negative direct effect on grain yield. A combination of high heritability and high direct on grain yield in 1000-grain weight and days to heading shows that those traits may be used in early-generation selection in breeding of highyielding facultative lines. The accession TX01D236 had a significantly higher grain yield compared to check varieties and could be included in future breeding work.

\section{REFERENCES}

Ahmadi, J., Vaezi, B., \& Pour-Aboughadareh, A. (2016). Analysis of variability, heritability, and interrelationships among grain yield and related characters in barley advanced lines. Genetika, 48(1):73-85.

Aklilu, E., Dejene, T., \& Worede, F. (2020). Genotypic and Phenotypic Correlation and Path Coefficient Analysis for Yield and Yield Related Traits in Barley (Hordeum vulgare L.) Landraces in North Gondar, Ethiopia. Ind. J. Pure App. Biosci, 8(3):24-36.

Al-Tabbal, J.A., \& Al-Fraihat, A.H. (2012). Genetic variation, heritability, phenotypic and genotypic correlation studies for yield and yield components in promising barley genotypes. Journal of Agricultural Science, 4(3):193.

Cruz, C.D. (2001). Program GENES-Version Windows: Computational Application in Genetics and Statistics. University of the Fraser Valley, Vicosa, p. 648

Deshmukh, S. N., Basu M. S. \& Reddy P. S. (1986). Genetic variability, character association and path coefficient analysis of quantitative traits in Viginia bunch varieties of ground nut. Ind. J. Agric. Sci. 56: 515-518.

Madić, M., Knežević, D., Đurović, D., Paunović, A., Stevović, V., Tomić, D., \& Đekić, V. (2019). Assessment of the correlation between grain yield and its components in spring barley on an acidic soil. Acta Agriculturae Serbica, 24(47):41-49.

Muñoz-Amatriaín, M., Cuesta-Marcos, A., Hayes, P. M., \& Muehlbauer, G. J. (2014). Barley genetic variation: implications for crop improvement. Briefings in functional genomics, 13(4):341-350.

Negash, G., Lule, D., \& Jalata, Z. (2019). Correlations and path Analysis of some quantitative characters in barley (Hordeum vulgareum L.) landraces in western Oromia, Ethiopia. African Journal of Plant Science, 13(2):34-46.

Neyhart, J.L., Lorenz, A.J., \& Smith, K.P. (2019). Multi-trait improvement by predicting genetic correlations in breeding crosses. G3: Genes, Genomes, Genetics, 9(10):3153-3165.

Sayd, R.M., Amabile, R.F., Faleiro, F.G., Costa, M.C., \& Montalvão, A.P.L. (2019). Genetic parameters and agronomic characterization of elite barley accessions under irrigation in the Cerrado. Acta Scientiarum. Agronomy, 41. 
Singh, B. D. (2001). Plant Breeding: Principles and Methods, 6th ed.Kalyani Publishers, New Delhi, p. 896.

SPSS (2008). Statistical package for Social Sciences, Statistics for Windows, Version 17.0. Released 2008. SPSS Inc., Chicago.

Tazeen, M., Nadia, K. \& Farzana, N.N., (2009). Heritability, phenotypic correlation and path coefficient studies for some agronomic characters in synthetic elite lines of wheat. J. Food. Agric. Environ. $7(3 \& 4): 278-282$.

von Zitzewitz, J., Szûcs, P., Dubcovsky, J., Yan, L., Francia, E., Pecchioni, N., Casas, A., Chen, T.H.H., Hayes P.M. \& Skinner J.S. (2005). Molecular and structural characterization of barley vernalization genes. Plant Mol. Biol. 59:449-467.

Zaefizadeh, M., Ghasemi, M., Azimi, J., Khayatnezhad, M., and Ahadzadeh, B. (2011). Correlation analysis and path analysis for yield and its components in hulless barley. Advances in Environmental Biology, 5(1):123-126. 